\title{
Clinical research
}

\section{Clinical neuropsychiatric considerations regarding nonsubstance or behavioral addictions}

Marc N. Potenza, $M D, P h D$

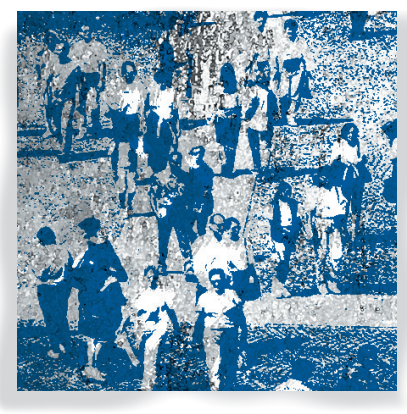

Over the past several decades, non-substance-use behaviors like gambling, gaming, and sex have received greater consideration as possible foci of addictions. In this article, I will review the recent history and current status of nonsubstance or behavioral addictions. A main focus will involve gambling and gambling disorder, given that the latter is currently the sole nonsubstance addictive disorder described in the main text of the current (fifth) edition of the Diagnostic and Statistical Manual of Mental Disorders (DSM-5). Internet gaming disorder, currently in the DSM-5 section addressing conditions that may need additional research, will also be considered, as will the concept of Internet addiction. Compulsive sexual behaviors (including problematic pornography use) will be considered, particularly with respect to how behavioral addictions may be considered in the forthcoming 11th edition of the International Classification of Diseases (ICD-11).

(๑) 2017, AICH - Servier Research Group

Dialogues Clin Neurosci. 2017;19:

Keywords: anxiety behavioral addiction; DSM; ICD-11; nonsubstance addiction

\author{
Introduction
}

he term "addiction" has undergone changes over time. The word is derived from a Latin word, $a d$ dicere, meaning "bound to" or "enslaved by," and in its initial formulation, it was not linked to substanceuse behaviors. ${ }^{1}$ Through the Middle Ages, it remained largely independent of substance-use behaviors, linked rather to "habits" or "penchants." In the 1700s, references to addictions were noted (eg, to tobacco), and throughout the 20th century, the term was applied to excessive/problematic use of opium and other drugs to the point that, during deliberations about the third edition revision of the Diagnostic and Statistical Manual of Mental Disorders (DSM-III-R), the Substance-Use Disorders (SUDs) Committee held that addiction could be defined as compulsive drug use., ${ }^{1,2}$ However, since that time, individuals have questioned whether non-substance-use behaviors (eg, gambling) can be considered as being addictive in nature. Some authors have proposed core features of addictions, including continued engagement in a behavior despite adverse consequences, diminished self-control over engagement

Author affiliations: Department of Psychiatry, Child Study Center, the $\mathrm{Na}$ tional Center on Addiction and Substance Abuse, Yale University School of Medicine and the Connecticut Mental Health Center, Connecticut, USA

Address for correspondence: Marc N. Potenza, MD, PhD, Connecticut Mental Health Center Room S-104, 34 Park Street, New Haven, CT 06519, USA

(email: marc.potenza@yale.edu) 


\section{Clinical research}

Selected abbreviations and acronyms

CD cocaine dependence

GD gambling disorder

HC healthy comparison

IGD Internet gaming disorder

$\boldsymbol{P G} \quad$ pathological gambling

SUD substance-use disorder

VS ventral striatum

in a behavior, an appetitive urge or craving state before such engagement, and compulsive engagement. ${ }^{3}$ If one considers these elements to be the central components of addiction, then an addiction framework may apply to a broader range of behaviors than those related to substance use. ${ }^{4}$

In the first decade of this millennium, there was an apparent shift in the support for conceptualizing nonsubstance-related behaviors as addictive. Two articles by Constance Holden published in Science bookend these changes. ${ }^{5,6}$ In the first, she asks whether behavioral addictions exist and whether new scientific techniques such as neuroimaging can provide evidence for shared neural circuitry in SUDs and, for example, pathological gambling (PG). In the second article, she heralds the reclassification of PG together with SUDs into the "Substance-related and Addictive Disorders" chapter of the $D S M-5 .{ }^{7}$ This reclassification was based in part on systematic reviews of the literature conducted in DSM-5 research workgroups comparing and contrasting $\mathrm{PG}$ and SUDs ${ }^{8}$ and PG and obsessive-compulsive disorder (OCD). ${ }^{9}$ The data indicated close similarities between PG and SUDs, but considerably less so between PG and $\mathrm{OCD}$, in multiple domains including diagnostic criteria, clinical characteristics, social factors, co-occurring disorders, personality features, behavioral measures, biochemistry, neurocircuitry, genetics, and treatments. ${ }^{8,9} \mathrm{As}$ such, PG (renamed "gambling disorder" [GD] in order to reduce potential stigma associated with the word "pathological") was reclassified together with SUDs in $D S M$-5, whereas other disorders that had been classified in the category of "Impulse Control Disorders Not Elsewhere Classified" either remained classified as impulse-control disorders or were reclassified elsewhere. ${ }^{7}$ Specifically, trichotillomania was reclassified together with OCD in the category of "Obsessive-Compulsive and Related Disorders." At the same time, the category of "Impulse Control Disorders Not Elsewhere
Classified" was renamed as "Disruptive, Impulse-Control and Conduct Disorders," with antisocial personality disorder, conduct disorder, and oppositional defiant disorder joining kleptomania, pyromania, and intermittent explosive disorder. ${ }^{7}$ In this data- and committeedriven manner, the category containing impulse-control disorders became more homogeneous with respect to including impulse-control disorders that involve "behaviors that violate the rights of others (eg, aggression, destruction of property) and/or bring the individual into significant conflict with societal norms of authority figures."

\section{Gambling}

For reasons noted, PG/GD may be considered the prototypical behavioral addiction. As such, it has been more studied than other behavioral addictions and will be a focus of this review. It is the only non-SUD included in DSM-5 in the "Substance-related and Addictive Disorders" section of the manual. ${ }^{7}$ From a clinical perspective, PG/GD and SUDs demonstrate frequent co-occurrence in clinical and community samples, show similar developmental patterns of expression (with high rates in adolescents and young adults and lower rates in older adults), show shared genetic and environmental contributions in twin studies, and demonstrate similarities, as well as differences, at neurobiological levels. ${ }^{8,10,11}$ Sex-related differences with respect to telescoping also seem to link PG/GD and SUDs (Box 1). ${ }^{12-20}$

Similarities between PG and SUDs have been reported for clinical interventions. For example, Gamblers Anonymous, modeled after Alcoholics Anonymous, is available worldwide and has been linked to favorable outcomes, particularly in conjunction with professional treatment. ${ }^{21}$ Behavioral therapies with efficacy in treating SUDs have been adapted for PG/ GD. For example, the cognitive behavioral therapy (CBT) approach used successfully in the treatment of SUDs has been adapted for PG/GD and shown to be efficacious. ${ }^{21}$ Pharmacotherapies with approval for SUDs have demonstrated positive results in placebocontrolled randomized clinical trials for PG/GD. Notably, naltrexone, an opioid-receptor antagonist with indications for alcohol- and opioid-use disorders, has demonstrated superiority over placebo in several randomized clinical trials, as has another opioid-receptor antagonist, nalmefene. ${ }^{21}$ However, there exist individual differences in responses that warrant additional in- 
vestigation and may highlight important links between gambling and SUDs. For example, among individuals with PG, those with a family history of alcoholism were more likely to respond to opioid-receptor antagonists than those without, suggesting that there may be shared biological features across alcohol-use disorders and PG that are effectively targeted by opioid-receptor antagonists. ${ }^{22}$ These findings resonate with those from a study of US veterans with co-occurring alcohol-use disorders and nongambling psychiatric disorders in which individuals with features of PG were less likely than those without such features to demonstrate clinical improvement in drinking when treated with disulfiram, whereas this effect was not observed in individuals treated with naltrexone. ${ }^{23}$ Like with alcohol-use disorders, opioidreceptor antagonists may operate through reductions in craving. ${ }^{22,24}$ However, in a negative placebo-controlled trial of as-needed naltrexone for the treatment of PG, a functional genetic polymorphism of the gene coding for the $\mu$-opioid receptor (A118G in the OPMR1 gene) that has been linked to alcohol-related treatment outcome in alcohol-use disorders ${ }^{25}$ was not linked to gambling-related outcomes. ${ }^{26}$ As such, the findings suggest similarities and differences between PG/GD and alcohol-use disorders, as have been suggested in studies of cognitive behavioral functioning and brain structure and function. For example, both groups of individuals with alcohol-use and gambling problems have been found to differ from healthy comparison (HC) subjects on measures of impulsivity and risky decision making, whereas individuals with alcohol-use disorders have been found to demonstrate more impairments on aspects of deliberation and working memory. ${ }^{27}$ These findings may relate to specific neurobiological correlates, as a recent study found that individuals with $\mathrm{PG}$, like those with cocaine dependence (CD), demonstrated differences in white-matter-related measures relating to secondary (crossing) fibers, whereas effects of alcohol-use disorders were more pronounced on primary tracts. ${ }^{28} \mathrm{In}$ addition to medications, nutraceuticals (over-the-counter dietary supplements) have been investigated in PG and SUDs, with $N$-acetylcysteine showing promise for both (Box 2). ${ }^{29-37}$

Factors that may link PG/GD and SUDs include shared genetic and/or environmental factors, and twin studies suggest that both contribute to the co-occurrence of PG/GD and SUDs (Box 3). ${ }^{38-51}$ Like with SUDs, specific neurotransmitters have been proposed to contribute to PG, with serotonin hypothesized to link to impulse control; dopamine, to reward-related behaviors; norepinephrine, to arousal and excitement; and opioids, to motivations and urges. ${ }^{52}$ Although some data support some of these relationships, the neurotransmitter contributions appear more complex and may differ from relationships in SUDs. For example, given multiple lines of evidence including the absence of differences in GD and $\mathrm{HC}$ groups on $\left[{ }^{11} \mathrm{C}\right]$-raclopride measures of $\mathrm{D}_{2}-$ like receptor availability, a central role for dopamine in the pathophysiology of GD has been questioned. ${ }^{53} \mathrm{Sim}$ ilarly, questions have been raised regarding the consis-

A "telescoping" phenomenon, initially described for substance-use disorders, has been observed in some, but not all, studies of pathological gambling/gambling disorder. ${ }^{12-16}$ This phenomenon was initially described for substance-use disorders and involves there being a shorter time period in females than in males in between the initiation of the addictive behavior and the development of a problem. ${ }^{17}$ The etiology of this sex-related difference is not known, but research into this phenomenon has been conducted. Although the genetic and environmental contributions to gambling disorder appear comparable in women and men, ${ }^{18,19}$ shared environmental factors appear to contribute more to age of gambling onset in women, and genetic factors appear to contribute more in men. ${ }^{20} \mathrm{~A}$ different pattern emerged for initiation of alcohol consumption in men in which age of first drink was related to shared environmental factors. ${ }^{20}$ However, in women, while shared environmental factors contributed to age at first drink, these were not correlated with those related to age at first gamble, similar to findings in the overall sample with respect to the contribution of unique environmental factors that contributed to age of first drink and age of first gamble, with these factors also being uncorrelated. ${ }^{20}$ Together, these findings suggest both similarities and differences in the sex-related differences in gambling and in alcohol-use behaviors and disorders, with a need for further research into the precise environmental genetic factors relating to these phenomena.

Box 1. Telescoping in pathological gambling/gambling disorder and substance-use disorders. 


\section{Clinical research}

tency of $\left[{ }^{11} \mathrm{C}\right]$-raclopride findings across SUDs, with the most consistent significant findings derived from studies of stimulant-use disorders. ${ }^{54}$ Findings from studies using a $\mathrm{D}_{3}$-preferring radioligand $\left[{ }^{11} \mathrm{C}\right]$-propyl-hexahydronaphtho-oxazin $\left(\left[{ }^{11} \mathrm{C}\right]-\mathrm{PHNO}\right)$ also point to differences between individuals with stimulant-use disorders and PG/GD. Specifically, several studies have identified between-group differences in individuals with and without stimulant-use disorders (particularly CD) with respect to $\left[{ }^{11} \mathrm{C}\right]-\mathrm{PHNO}$ availability in the substantia nigra, ${ }^{55-58}$ whereas these effects were not observed in individuals with and without PG/GD ${ }^{59}$ Together, these findings suggest that some of the dopamine-related findings in addictions may relate to specific substances, with stimulants such as cocaine possibly having direct effects on dopamine systems. Additionally, findings of differen- tial $\left[{ }^{11} \mathrm{C}\right]$-raclopride binding, particularly in the ventral striatum (VS), have been reported in individuals with Parkinson disease (PD) with and without PG. ${ }^{60}$ As such findings have not been observed in non-PD individuals with and without $\mathrm{PG}$, it raises questions regarding how factors related to PD (eg, dopamine-related pathology) may influence the neural mechanisms underlying PG in $\mathrm{PD}$ and cautions against generalizing findings in PD to non-PD populations. These findings suggest that other neurotransmitter systems warrant investigation in PG/ GD, with recent studies observing differences between individuals with and without GD with respect to opioidergic and $\gamma$-aminobutyric acid (GABA)-ergic receptor availabilities. ${ }^{61,62}$

Functional magnetic resonance imaging (fMRI) findings suggest similarities across PG/GD and SUDs,

Another clinical intervention suggesting similarities between pathological gambling/gambling disorder and substance-use disorders involves the nutraceutical $N$-acetylcysteine (NAC), an amino acid that is an over-thecounter dietary supplement. NAC has been reported to have a proposed mechanism of action in treating addictions through influences on glutamatergic systems, particularly mGluR2 and mGluR3 receptors. ${ }^{30-33}$ In an open-label study followed by placebo-controlled double-blind discontinuation, active NAC was superior to placebo in maintaining diminished problem-gambling severity ${ }^{34}$ A subsequent study of individuals with cooccurring pathological gambling and nicotine dependence investigated the efficacy and tolerability in reducing problematic gambling and smoking. ${ }^{29}$ In this study, all participants received a behavioral therapy involving aspects of cognitive behavioral therapy, imaginal desensitization, and motivational interviewing targeting pathological gambling and a behavioral therapy for smoking cessation. Additionally, NAC was administered in a placebo-controlled, double-blind fashion. The findings indicated that active NAC was superior to placebo in reducing smoking severity within the 12 -week treatment period and was superior to placebo in reducing problem-gambling severity at the 24-week follow-up assessment. ${ }^{29}$ This finding raises the question whether NAC may help improve treatment outcome for pathological gambling by augmenting a "sleeper effect" that has been reported for certain behavioral therapies, notably cognitive behavioral therapy, in the treatment of drug addictions. ${ }^{35}$ That is, cognitive behavioral therapy appears particularly durable, perhaps because people may continue to practice and utilize approaches to remain abstinent. Another non-mutually exclusive possibility is that NAC, like opioid-receptor antagonists, may help reduce cravings across addictive disorders, consistent with findings in studies of both pathological gambling and substance-use disorders. For example, NAC was superior to placebo in reducing gambling-related thoughts and urges in pathological gambling, ${ }^{29}$ consistent with trend findings in a smaller previous study ${ }^{34}$ and findings reported for substance-use disorders. For example, in a review of studies of NAC for cocaine dependence, NAC was linked to reduced craving and desire to use cocaine. ${ }^{33}$ In a study investigating the neural mechanisms for NAC's effects on tobacco-related phenomena in smokers, administration of NAC versus placebo for several days was associated with less craving, more positive affect, and stronger resting-state functional connectivity in regions including the ventral striatum, medial prefrontal cortex, precuneus, and cerebellum. ${ }^{36}$ Additional studies are needed to examine the longer-term effects of NAC on different groups of individuals with addictions, including gambling disorder. Furthermore, the extent to which co-occurring substance-use disorders may be used to guide selection of therapies for individuals with gambling disorder requires further examination. ${ }^{37}$

Box 2. $\mathrm{N}$-acetylcysteine in the treatment of pathological gambling/gambling disorder and substance-use disorders. 
as well as differences, with respect to specific cognitive domains, including reward processing, cognitive control, and craving. ${ }^{11,63,64}$ With respect to reward processing, blunted activation of the VS during the anticipatory phase of reward processing has been observed in several, ${ }^{65,66}$ but not all, ${ }^{67}$ studies of PG, with the former results similar to findings in other SUDs involving alcohol and tobacco use. ${ }^{6}$ Impulsivity may be a factor linking $\mathrm{PG} / \mathrm{GD}$ and alcohol-use disorders during reward processing, as it was inversely related to VS activation during anticipatory reward processing in both disorders. ${ }^{66,69}$ During the outcome phase of reward processing, relatively diminished activation of the ventromedial prefrontal cortex (vmPFC) was observed in PG subjects, ${ }^{66}$ consistent with findings of relatively reduced activation of this region in PG subjects in other contexts, including cognitive control, ${ }^{70}$ craving, ${ }^{71}$ riskreward decision making, ${ }^{72}$ and simulated gambling. ${ }^{73}$ A recent study of gambling-cue-elicited craving iden- tified elevated activation of the insula and cingulate/ dorsal PFC in individuals with GD, with the craving to gamble associated positively with functional connectivity between the insula and VS and negatively with functional connectivity between the VS and medial prefrontal cortex (mPFC). ${ }^{74}$ These findings resonate with a recent craving study that observed in PG subjects a gambling-cue-elicited increase in dorsal mPFC, as well as insular activation in women with $\mathrm{PG}^{75} \mathrm{In}$ vestigation into how genetic differences may relate to brain function and behavior have begun for PG/GD (Box 4). ${ }^{76-78}$

Recent studies have begun to directly investigate similarities and differences in brain function and structure in PG/GD and SUD groups. For example, a cueinduced craving study identified a group (PG, $\mathrm{CD}$, and $\mathrm{HC}$ ) by condition (gambling, cocaine-related, and sad cues) interaction implicating ventral and dorsal mPFC, with the former demonstrating increased activation in

In a sample of male twins, both genetic and environmental factors have been found to contribute to the cooccurrence of pathological gambling/gambling disorder with alcohol-use, tobacco-use, and cannabis-use disorders, whereas the co-occurrence of pathological gambling/gambling disorder with stimulant-use disorders was predominantly genetic in nature. ${ }^{38,39}$ These findings raise the possibility that more socially accepted substances are linked to pathological gambling/gambling disorder in a manner that is more closely linked to environmental influences. Such environmental influences may be particularly important for women, whereas in men, larger genetic contributions to the co-occurrence of gambling disorder and alcohol-use disorders have been noted..$^{40}$ The specific environmental factors that may contribute to gambling disorder may include trauma and social disadvantage. For example, trauma has been linked to pathological gambling, ${ }^{41}$ particularly in women.$^{42}$ Geneenvironment interactions indicating higher frequency of slot-machine gambling among both men and women and more frequent gambling disorder symptoms in women have been reported with respect to degree of neighborhood social disadvantage. ${ }^{43}$ In other words, findings suggest that potential genetic risks for gambling disorder may be expressed behaviorally to a greater degree in individuals exposed to social disadvantage. Specific epigenetic influences have only recently been investigated in gambling disorder, with initial findings suggesting that methylation of $D R D 2$ (the gene coding for the dopamine $\mathrm{D}_{2}$ receptor proposed to be linked to addictive behaviors and disorders including pathological gambling, ${ }^{44}$ although such effects have been questioned as it is in linkage disequilibrium with $A N K K 1$, which appears to associate more closely with alcohol- and tobacco-use disorders, ${ }^{45,46}$ perhaps in part through influences on $\beta 2$-nicotinic acetylcholine receptors ${ }^{47}$ ) may depend on treatment status and transdiagnostic features, with lower methylation observed in abstinent individuals in treatment and with findings driven predominantly by impulsive individuals. ${ }^{48,49}$ Additional research is needed to identify specific genes associated with gambling disorder and how their expression may be influenced by specific environmental exposures in order to identify factors and pathways related to both vulnerability and resiliency. To date, two genome-wide association studies have not identified specific genomic regions reaching genome-wide significance for gambling disorder. ${ }^{50,51}$ However, in one study, polygenic risk scores for alcohol-use disorders and gambling disorder were correlated ${ }^{51}$ consistent with previous findings suggesting shared contributions to the disorders. ${ }^{38}$

Box 3. Genetic and environmental contributions to pathological gambling/gambling disorder and substance-use disorders. 


\section{Clinical research}

the addicted subjects in response to cocaine cues and the latter showing increased activation in a diagnosisand cue-specific manner (PG in response to gambling cues; $\mathrm{CD}$, to cocaine cues; and $\mathrm{HC}$, to sad cues). ${ }^{75}$ In a study of processing wins, losses, and other events during a simulated slot-machine fMRI task, PG showed greater VS activation than $\mathrm{HC}$ subjects during possibly rewarding events (ie, when the first two slot-maching reels matched), whereas $\mathrm{CD}$ subjects showed relatively less VS activation than $\mathrm{HC}$ subjects when processing sure losses (ie, when the first two reels did not match). ${ }^{79}$ During processing of "near-misses" (when two of three reels matched) versus full losses (ie, when no reels matched), a similar pattern emerged in the vmPFC. ${ }^{79}$ These findings suggest that gambling-related reward processing may be more focused on possible wins in PG subjects and on possible losses in CD subjects. During a loss-chasing task (involving starting with a loss and having options to make successive "double-or-nothing" gambles or accepting a loss), CD and PG subjects showed differences from $\mathrm{HC}$ subjects in different periods of decision making. ${ }^{80}$ Specifically, PG subjects showed greater engagement of an $\mathrm{mPFC}$ circuit than $\mathrm{HC}$ and $\mathrm{CD}$ subjects before making decisions to quit chasing, whereas CD subjects showed less engagement than $\mathrm{HC}$ subjects of an amygdalar-striatal circuit. ${ }^{80}$ These findings highlight important similarities and differences in motivational and reward/loss-related processes across PG and CD.
A diffusion tensor imaging study observed similar differences in PG and CD subjects (as compared with HC subjects) in secondary (crossing) fibers in corticostriatal and parieto-occipital tracts, suggestive of similar patterns of poorer white-matter integrity in the addicted groups in tracts previously implicated in connecting brain regions involved in reward processing and addictions. ${ }^{28}$ An investigation of gray-matter volume in PG, $\mathrm{CD}$, and $\mathrm{HC}$ subjects found that in comparison with PG and HC groups, the CD group showed diminished frontal cortical volumes, whereas impulsivity across all three groups was correlated inversely with volumes of the insula and subcortical regions (amygdala, hippocampus). ${ }^{81}$ These findings suggest that some neurobiological findings link more closely to diagnostic groupings (which in this case may relate to neurotoxic effects of cocaine ${ }^{82}$ although this possibility is speculative and warrants direct examination in longitudinal studies), whereas others link more closely to transdiagnostic measures, with the latter being consistent with RDoC (Research Domain Criteria) considerations. ${ }^{83,84}$

Although many models for SUDs have historically been applied to PG/GD, one should be cautious in this process. For example and as noted earlier, an arguably widespread conceptualization of the centrality of dopamine to addictions has been questioned for both PG/ GD and a broad range of SUDs, ${ }^{53,54}$ and genetic studies of SUDs have often identified genes involved in substance metabolism. As such, an overarching biological

Several studies using candidate gene approaches targeting commonly occurring allelic variants with known functional implications have been conducted. For example, an fMRI study of subjects with pathological gambling and healthy comparison (HC) subjects was conducted to investigate how emotional and motivational processing may by modified by a functional allelic polymorphism (rs161115) of $D B H$, the gene encoding the enzyme dopamine- $\beta$ hydroxylase (DBH), which accounts for $35 \%$ to $52 \%$ of DBH's enzymatic activity in dopamine/norepinephrine conversion. ${ }^{76}$ In prior studies, the T allele has been associated with less enzymatic activity, less empathy, lower conscientiousness, more novelty seeking, and greater drug-use severity, leading to hypothesized involvement of corticostriatolimbic brain regions and influences on affective processing across diagnostic groups. ${ }^{76}$ Behavioral and brain responses were identified, with T-carriers demonstrating lower subjective reports of sadness in response to the sad cues and less activation of corticostriatolimbic brain regions, particularly during sad cues. ${ }^{76}$ In a separate study, a functional allele (Val-158-Met, with the Met allele associated with $40 \%$ less activity) of $C O M T$, the gene encoding the enzyme catechol- $O$-methyltransferase (COMT), was investigated in individuals receiving treatment for pathological gambling. ${ }^{77}$ The Met allele was associated with poorer treatment outcome with the COMT inhibitor tolcapone. ${ }^{77}$ As the COMT Met/Met genotype has been linked both to problem-gambling and problem-drinking severities, it may have important implications for the treatment of both pathological gambling/gambling disorder and alcohol-use disorders. ${ }^{78}$

Box 4. Initial investigations into genetic influences on neural functioning in pathological gambling/gambling disorder. 
and/or neural model for PG/GD and differences from those for SUDs may currently be premature or speculative. That said, data from studies directly comparing and contrasting PG/GD and SUDs will provide important insight, particularly as imaging studies employing larger sample sizes are conducted and analytic approaches that generate more stable and replicable results are used. Such a process should help more precisely specify the neural and neurochemical similarities and differences between PG/GD and SUDs.

\section{Internet use and gaming}

As the Internet has grown in availability and usage, the degree to which certain behaviors on the Internet might be problematic or addictive has been considered. Whereas initial studies largely focused on types and patterns of Internet use more generally (ie, "Internet addiction" ${ }^{85}$ ), a more recent focus has been on the types of behaviors performed on the Internet. Of particular note is gaming. The DSM-5 SUD workgroup considered Internet use and gaming and proposed that provisional criteria for Internet gaming disorder (IGD) be included in section 3 of $D S M-5$, a section intended to address conditions warranting additional research. ${ }^{86}$ The decision to focus on gaming was made given that more data were available on problems with Internet gaming than with other forms of Internet use at the time, although currently, a broader range of Internetrelated behaviors (eg, social networking, gambling, pornography viewing, shopping) are currently being investigated. ${ }^{87}$ The criteria for IGD bear similarities to those for GD and involve clinically significant impairment or distress related to meeting five (or more) of ten inclusionary criteria relating to such features as tolerance, withdrawal, preoccupation, and interference in major areas of life functioning. ${ }^{7}$ Although the proposed diagnostic entity has brought more consistency to the assessment of IGD, debates remain. For example, some scholars believe that recognizing IGD as a diagnostic entity has negative implications for individuals who participate in gaming, ${ }^{88}$ whereas others believe that having a formal diagnostic entity will help promote public health efforts relating to policies, prevention, and treatment. ${ }^{89}$ The proposed criteria for gaming disorder being considered for the 11th edition of the International Classification of Diseases (ICD-11) are available online (at the time of this writing; http://apps.who.int/ classifications/icd11/browse/f/en\#/http \%3a \%2f\%2fid. who.int \%2ficd\%2fentity\%2f1448597234). Key features include interference in major areas of functioning related to gaming (ie, videogaming), with persistent and recurrent gaming over a period of at least 12 months that continues despite adverse consequences and in the setting of impaired control over gaming. Specifiers (those predominantly online and those predominantly offline) have been proposed, as has a mutually exclusive category of hazardous gaming meant to capture individuals who engage in types and patterns of gaming that may place them at increased risk for mental or physical health problems but have yet to reach the level of gaming disorder (http://apps.who.int/classifications/ icd11/browse/f/en\#http \% 3a \%2f\%2fid.who.int \%2ficd $\% 2$ fentity\%2f1586542716). These features, specifiers, and mutually exclusive behaviors also exist currently in beta-draft format for the proposed criteria for GD in ICD-11, with classification of both disorders with SUDs in a proposed grouping of "Disorders Due to Substance Use or Addictive Behaviours."

Despite the debates, ${ }^{88,89}$ considerable research is being conducted into IGD, including investigation of effective treatments and neurobiological underpinnings, with both similarities and differences between IGD, GD, and SUDs noted..$^{90}$ Nonetheless, studies are still at an early stage, often with small sample sizes and other limitations. ${ }^{91}$ With respect to treatments, few have been tested formally, with early studies of cognitive behavioral therapies showing some promise for IGD and Internet addiction more broadly. ${ }^{92,93}$ Initial studies have begun to probe possible neural mechanisms underlying effective treatments for IGD. For example, a craving behavioral intervention (CBI) involving elements of cognitive behavioral therapy and mindfulness, in comparison with a test-retest condition, was found to lead to reductions in Internet-addiction severity, time spent gaming, and cue-induced gaming-related craving. ${ }^{93}$ The CBI intervention group relative to the test-retest group also showed increased insula activation from gamingrelated cues after the intervention, with decreased functional activity between the insula and the precuneus and lingual gyrus also noted after treatment. ${ }^{93} \mathrm{Ad}-$ ditionally, resting-state findings suggested that CBI decreased connectivity between the orbitofrontal cortex and hippocampus and between the posterior cingulate and motor-related brain regions. ${ }^{94}$ These findings suggest that the CBI may work in part by decreasing the 


\section{Clinical research}

strength of connectivity during cue exposure and at rest between regions implicated in cue-induced craving in SUDs and GD. Other constructs (eg, cognitive control, risk-reward decision making) have been proposed as potential treatment targets in IGD ${ }^{95}$ and fMRI investigations have identified differences in neural correlates of these processes in individuals with and without IGD. ${ }^{96,97}$ As such, their potential targeting in clinical investigations warrants direct examination.

\section{Sex}

Both Internet-based and non-Internet-based forms of problematic sexual behaviors warrant clinical consideration and investigation. Hypersexual disorder was considered for inclusion in DSM-5 and, despite field testing having been conducted, it was not included. ${ }^{98}$ Currently, there is a beta-draft version of a diagnostic entity called "compulsive sexual behavior disorder" (CSB) being proposed for inclusion in the ICD-11 (http://apps.who.int/ classifications/icd11/browse/f/en\#/http \%3a \% 2f\%2fid. who.int $\% 2$ ficd $\% 2$ fentity $\% 2 f 1630268048$ ). Features of the proposed disorder include a "persistent pattern of failure to control intense, repetitive sexual impulses or urges" that involves preoccupation, unsuccessful attempts to control sexual behaviors, and sexual engagement despite adverse consequences, with a proposed time frame of at least 12 months and the association with significant distress or impairment in major areas of life functioning. Despite the similarities in the descriptions of CSB and GD, gaming disorder, and SUDs and the inclusion of core elements of addictions in CSB, CSB is currently being proposed for classification as an "Impulse Control Disorder" in ICD-11, together with pyromania, kleptomania, and intermittent explosive disorder. This approach may reflect ongoing debates regarding the most appropriate classification of $\mathrm{CSB}$, as well as the limited amount of data regarding CSB in many domains, including effective treatments and prevalence estimates. ${ }^{99,100}$

One area that has received considerable research attention is the neurobiology of CSB. ${ }^{101}$ For example, in a comparison of heterosexual men with and without CSB, those with CSB have shown greater activation in the amygdala, VS, and anterior cingulate to sexually explicit cues, with the functional connectivity in these regions associated with sexual desire to a greater degree in CSB versus non-CSB men. ${ }^{102}$ In heterosexual men either with or without problematic pornography use (PPU), those with PPU demonstrated greater VS activation to cues predicting erotic rewards than those predicting monetary rewards. ${ }^{103}$ In both studies, consistencies with incentive-salience theories of addiction were described. Other studies suggest attentional biases in CSB similar to those reported in addictions. ${ }^{104,105}$ Preliminary data suggest that naltrexone may be helpful for reducing urges/cravings in the treatment of PPU. ${ }^{106}$ Although preliminary and predominantly involving heterosexual males, data suggest multiple similarities between CSB and addictive disorders like GD and SUDs.

\section{Conclusion and future directions}

Although the field of behavioral addictions continues to develop, it is still young, and there are many gaps remaining in what is currently known and in clinical practice. Despite the increase in understanding of the biological underpinnings of PG/GD over the past several decades, the translation of this information into improved prevention and treatment strategies has been slow, with no medications approved by the US Food and Drug Administration at the time of this writing. Additionally, given the current structure of the US National Institutes of Health, which includes separate institutes focusing on alcohol- and drug-use disorders and none that focus on other addictions, no institute has behavioral addictions as a research priority. ${ }^{107}$ As such, in the United States, progress in understanding the biological processes driving behavioral addictions will probably be slower than for other psychiatric disorders, with the potential to lead to health disparities for people with behavioral addictions (and others affected, such as family members). Nonetheless, with research being conducted worldwide and technological advances leading to more refined understandings of the individual differences related to the development and persistence of and recovery from behavioral addictions, there is reason to remain hopeful that advances toward individualized and more effective care will be made, and also that there will be improved approaches for prevention of, treatment of, and policies concerning behavioral addictions in the future. $\square$

Acknowledgments/Conflict of Interest/Funding sources: Dr Potenza declares no conflicts of interest. Dr Potenza has consulted for and advised INSYS, Shire, RiverMend Health, Opiant/Lakelight Therapeutics, and Jazz 
Pharmaceuticals; has received research support from the Mohegan Sun Casino, the National Center for Responsible Gaming, and Pfizer; has participated in surveys, mailings, or telephone consultations related to drug addiction, impulse-control disorders, or other health topics; has consulted for gambling and legal entities on issues related to impulse-control and addictive disorders; provides clinical care in the Connecticut Department of Mental Health and Addiction Services Problem Gambling Services Program; has performed grant reviews for the National Institutes of Health

\section{REFERENCES}

1. Douglas Harper, Historian. Definition of addiction. Dictionary.com. Online Etymology Dictionary. Available at: http://www.dictionary.com/ browse/addiction. Accessed March 26, 2017.

2. O'Brien CP, Volkow N, Li TK. What's in a word? Addiction versus dependence in DSM-V. Am J Psychiatry. 2006;163(5):764-765.

3. Potenza MN. The neurobiology of pathological gambling and drug addiction: an overview and new findings. Phil Trans $R$ Soc $B$. 2008;363(1507):3181-3189.

4. Grant JE, Potenza MN, Weinstein A, Gorelick DA. Introduction to behavioral addictions. Am J Drug Alcohol Abuse. 2010;36(5):233-241.

5. Holden C. 'Behavioral' addictions: do they exist? Science. 2001;294(5544):980-982.

6. Holden C. Behavioral addictions debut in proposed DSM-V. Science. 2010;327(5968):935.

7. American Psychiatric Association. Diagnostic and Statistical Manual of Mental Disorders. 5th ed. Washington, DC: American Psychiatric Association; 2013.

8. Potenza MN. Should addictive disorders include non-substance-related conditions? Addiction. 2006:101(suppl 1):142-151.

9. Potenza MN, Koran LM, Pallanti S. The relationship between impulse control disorders and obsessive-compulsive disorder: a current understanding and future research directions. Psychiatry Res. 2009;170(1):22-31. 10. Petry NM. Should the scope of addictive behaviors be broadened to include pathological gambling? Addiction. 2006:101(suppl 1):152-160.

11. Fauth-Bühler M, Mann K, Potenza MN. Pathological gambling: a review of the neurobiological evidence for its classification as an addictive disorder. Addict Biol. 2016 Mar 3. Epub ahead of print. doi:10.1111/ adb.12378

12. Potenza MN, Steinberg MA, McLaughlin SD, Wu R, Rounsaville BJ, O'Malley SS. Gender-related differences in the characteristics of problem gamblers using a gambling helpline. Am J Psychiatry. 2001;158(9):15001505.

13. Tavares H, Zilberman ML, Beites FJ, Gentil V. Gender differences in gambling progression. J Gamb/ Stud. 2001;17(2):151-160.

14. Grant J, Kim SW. Gender differences in pathological gamblers seeking medication treatment. Compr Psychiatry. 2002;43(1):56-62.

15. Grant JE, Odlaug BL, Mooney ME. Telescoping phenomenon in pathological gambling: association with gender and comorbidities. J Nerv Ment Dis. 2012;200(11):996-998.

16. Slutske WS, Piasecki TM, Deutsch AR, Statham DJ, Martin NG. Telescoping and gender differences in the time course of disordered gambling: evidence from a general population sample. Addiction. 2015;110(1):144151.

17. Randall C, Robert JS, Del Boca FK, Carroll KM, Connor GJ, Mattson ME. Telescoping of landmark events associated with drinking: a gender comparison. J Stud Alcohol. 1999;60(2):252-260.

18. Slutske WS, Zhu G, Meier MH, Martin NG. Genetic and environmental influences on disordered gambling in men and women. Arch Gen Psychiatry. 2010;67(6):624-630.

19. Slutske WS, Richmond-Rakerd LS. A closer look at the evidence for sex differences in the genetic and environmental influences on gambling in the National Longitudinal Study of Adolescent Health: From dis-ordered to ordered gambling. Addiction. 2015;109(1):120-127.

20. Richmond-Rakerd LS, Slutske WS, Heath AC, Martin NG. Genetic and environmental influences on the ages of drinking and gambling initiation: evidence for distinct etiologies and sex differences. Addiction. 2014;109(2):323-331. and other agencies; has edited journals or journal sections; has given academic lectures in grand rounds, CME events, and other clinical or scientific venues; and has generated books or book chapters for publishers of mental health texts. Dr Potenza's involvement was supported through the National Center for Responsible Gaming Center of Excellence grant and from the National Center on Addiction and Substance Abuse. The content of the manuscript does not necessarily reflect the views of any of the funding agencies.

21. Yip SW, Potenza MN. Treatment of gambling disorders. Curr Treat Options Psychiatry. 2014;1(2):189-203.

22. Grant JE, Kim SW, Hollander E, Potenza MN. Predicting response to opiate antagonists and placebo in the treatment of pathological gambling. Psychopharmacology (Berl). 2008;200(4):521-527.

23. Grant JE, Potenza MN, Kraus SW, Petrakis IL. Naltrexone and disulfiram treatment response in veterans with alcohol dependence and $\mathrm{CO}^{-}$ occurring gambling problems. J Clin Psychiatry. In press.

24. Maisel NC, Blodgett JC, Wilbourne PL, Humphreys K, Finney JW. Meta-analysis of naltrexone and acamprosate for treating alcoho use disorders: when are these medications most helpful? Addiction. 2013;108(2):275-293.

25. Oslin DW, Berrettini W, Kranzler HR, et al. A functional polymorphism of the $\mu$-opioid receptor gene is associated with naltrexone response in alcohol-dependent patients. Neuropsychopharmacology. 2003;28(8):15461552.

26. Kovanen L, Basnet S, Castrén S, et al. A randomised, double-blind, placebo-controlled trial of as-needed naltrexone in the treatment of pathological gambling. Eur Addict Res. 2016;22(2):70-79.

27. Lawrence AJ, Luty J, Bogdan NA, Sahakian BJ, Clark L. Problem gamblers share deficits in impulsive decision-making with alcohol-dependent individuals. Addiction. 2009;104(6):1006-1015.

28. Yip SW, Morie KP, Xu J, et al. Shared microstructural features of behavioral and substance addictions revealed in areas of crossing fibers. Biol Psychiatry Cogn Neurosci Neuroimaging. 2017;2(2):188-195.

29. Grant JE, Odlaug BL, Chamberlain SR, et al. A randomized, placebocontrolled trial of $\mathrm{N}$-acetylcysteine plus imaginal desensitization for nicotine-dependent pathological gamblers. J Clin Psychiatry. 2014;75(1):3945

30. Kalivas PW, Volkow ND. The neural basis of addiction: a pathology of motivation and choice. Am J Psychiatry. 2005;162(2):1403-1413.

31. LaRowe SD, Mardikian P, Malcolm R, et al. Safety and tolerability of $\mathrm{N}$-acetylcysteine in cocaine-dependent individuals. Am J Addict. 2006;15(1):105-110.

32. LaRowe SD, Myrick $H$, Hedden $S$, et al. Is cocaine desire reduced by $\mathrm{N}$-acetylcysteine? Am J Psychiatry. 2007;164(7):1115-1117.

33. Nocito Echevarria MA, Andrade Reis T, Ruffo Capatti G, Siciliano Soares V, da Silveira DX, Fidalgo TM. $N$-acetylcysteine for treating cocaine addiction - a systematic review. Psychiatry Res. 2017;251:197-203.

34. Grant JE, Kim SW, Odlaug BL. N-Acetyl cysteine, a glutamate-modulating agent, in the treatment of pathological gambling: a pilot study. BiO/ Psychiatry. 2007;62(6):652-657.

35. Carroll K, Fenton LR, Ball SA, et al. Efficacy of disulfiram and cognitive-behavioral therapy in cocaine-dependent outpatients. Arch Gen Psychiatry. 2004;61(3):264-272.

36. Froeliger B, McConnell PA, Stankeviciute N, McClure EA, Kalivas PW, Gray KM. The effects of $\mathrm{N}$-acetylcysteine on frontostriatal resting-state functional connectivity, withdrawal symptoms and smoking abstinence: a double-blind, placebo-controlled fMRI pilot study. Drug Alcohol Depend. 2015;156:234-242.

37. Dowling NA, Merkouris SS, Lorains FK. Interventions for comorbid problem gambling and psychiatric disorders: advancing a developing field of research. Addict Behav. 2016;58:21-30.

38. Slutske WS, Eisen S, True WR, Lyons MJ, Goldberg J, Tsuang M. Common genetic vulnerability for pathological gambling and alcohol dependence in men. Arch Gen Psychiatry. 2000;57(7):666-674.

39. Xian $\mathrm{H}$, Giddens J, Scherrer J, Eisen SA, Potenza MN. Environmental factors selectively impact co-occurrence of problem/pathological gambling with specific drug-use disorders. Addiction. 2014;109(4):635-644. 


\section{Clinical research}

40. Slutske WS, Ellingson JM, Richmond-Rakerd LS, Zhu G, Martin NG. Shared genetic vulnerability for disordered gambling and alcohol use disorder in men and women: evidence from a national community-based australian twin study. Twin Res Hum Gen. 2013;16(2):525-534.

41. Scherrer JF, Xian H, Kapp JM, et al. Association between exposure to childhood and lifetime traumatic events and lifetime pathological gambling in a twin cohort. J Nerv Ment Dis. 2007;195(1):72-78.

42. Petry NM, Steinberg KL. Childhood maltreatment in male and female treatment-seeking pathological gamblers. Psychol Addict Behav. 2005; 19(2):226-229.

43. Slutske WS, Deutsch AR, Statham DB, Martin NG. Local area disadvantage and gambling involvement and disorder: evidence for gene-environment correlation and interaction. J Abnorm Psychol. 2015;124(3):606-622.

44. Comings DE. The molecular genetics of pathological gambling. CNS Spectrums. 1998;3(6):20-37.

45. Yang BZ, Kranzler HR, Zhao H, Gruen JR, Luo X, Gelernter J. Association of haplotypic variants in DRD2, ANKK1, TTC12 and NCAM1 to alcoho dependence in independent case-control and family samples. Hum $\mathrm{Mol}$ Genet. 2007;16(23):2844-2853

46. Gelernter J, Yu Y, Weiss R, et al. Haplotype spanning $T T C 12$ and ANKK1, flanked by the DRD2 and NCAM1 loci, is strongly associated to nicotine dependence in two distinct American population. Hum Mol Genet. 2006;15(24):3498-3507.

47. Esterlis I, Hillmer AT, Bois $\mathrm{F}$, et al. CHRNA4 and ANKK1 polymorphisms influence smoking-induced nicotinic acetylcholine receptor upregulation. Nicotine Tob Res. 2016;18(9):1845-1852.

48. Hillemacher $\mathrm{T}$, Frieling $\mathrm{H}$, Buchholz $\mathrm{V}$, et al. Alterations in DNAmethylation of the dopamine-receptor 2 gene are associated with abstinence and health care utilization in individuals with a lifetime history of pathologic gambling. Prog Neuropsychopharmacol Biol Psychiatry. 2015:63:30-34.

49. Hillemacher $T$, Frieling $H$, Buchholz $V$, et al. Dopamine-receptor 2 gene-methylation and gambling behavior in relation to impulsivity. Psychiatry Res. 2016;239:154-155.

50. Lind PA, Zhu G, Montgomery GW, et al. Genome-wide association study of a quantitative disordered gambling trait. Addiction Biology. 2013;18(3):511-522.

51. Lang $M$, Leménager T, Streit $F$, et al. Genome-wide association study of pathological gambling. Eur Psychiatry. 2016;36:38-46.

52. Potenza MN, Hollander E. Pathological gambling and impulse control disorders. In: Davis K, Charney D, Coyle JT, Nemeroff C, eds. Neuropsychopharmacology: the 5th Generation of Progress. Philadelphia, PA: Lippincott, Williams, \& Wilkins; 2002.

53. Potenza MN. How central is dopamine to pathological gambling or gambling disorder? Front Behav Neurosci. 2013;7:206.

54. Nutt DJ, Lingford-Hughes A, Erritzoe D, Stokes PR. The dopamine theory of addiction: 40 years of highs and lows. Nat Rev Neurosci. 2015;16(5):305-312.

55. Matuskey D, Gallezot JD, Pittman B, et al. Dopamine $D_{3}$ receptor alterations in cocaine-dependent humans imaged with the PET ligand $\left[{ }^{11} \mathrm{C}\right]$ (+)PHNO. Drug Alcohol Depend. 2014;139:100-105.

56. Worhunsky PD, Matuskey D, Gallezot JD, et al. Altered regional and network-based patterns of dopamine D2/D3 receptors in cocaine use disorder. Neuroimage. 2017;148:343-351.

57. Payer DE, Behzadi A, Kish SJ, et al. Heightened $D_{3}$ dopamine receptor levels in cocaine dependence and contributions to the addiction behavioral phenotype: a positron emission tomography study with $\left[{ }^{11} \mathrm{C}\right]-(+)-$ PHNO. Neuropsychopharmacology. 2014;39(2):311-318.

58. Boileau I, Payer $D$, Houle $S$, et al. Higher binding of the dopamine $D_{3}$ receptor-preferring ligand $\left[{ }^{11} \mathrm{C}\right]-(+)-P H N O$ in methamphetamine polydrug users: a positron emission tomography study. J Neurosci. 2012;32(4):13531359.

59. Boileau I, Payer D, Chugani $B$, et al. The $D_{2 / 3}$ dopamine receptor in pathological gambling: a positron emission tomography study with $\left[{ }^{11} \mathrm{C}\right]-$ (+)-propyl-hexahydro-naphtho-oxazin and $\left[{ }^{11} \mathrm{C}\right]$ raclopride. Addiction. 2013;108(5):953-963.

60. Steeves TDL, Miyasaki J, Zurowski M, et al. Increased striatal dopamine release in Parkinsonian patients with pathological gambling: a $\left[{ }^{11} \mathrm{C}\right]$ raclopride PET study. Brain. 2009;132(pt 5):1376-1385.
61. Mick I, Myers J, Ramos AC, et al. Blunted endogenous opioid release following an oral amphetamine challenge in pathological gamblers. Neuropsychopharmacology. 2016;41(7):1742-1750.

62. Mick I, Ramos AC, Myers J, et al. Evidence for GABA-A receptor dysregulation in gambling disorder: correlation with impulsivity. Addict Biol. 2016 Oct 13. Epub ahead of print. doi:10.1111/adb.12457.

63. Leeman RF, Potenza MN. Similarities and differences between pathological gambling and substance use disorders: a focus on impulsivity and compulsivity. Psychopharmacology (Berl). 2012;219(2):469-490.

64. Leeman RF, Potenza MN. A targeted review of the neurobiology and genetics of behavioral addictions: an emerging area of research. Can $J$ Psychiatry. 2013;58(5):260-273.

65. Choi JS, Shin YC, Jung WH, et al. Altered brain activity during reward anticipation in pathological gambling and obsessive-compulsive disorder. PLoS One. 2012;7(9):e45938.

66. Balodis IM, Kober H, Worhunsky PD, Stevens MC, Pearlson GD, Potenza MN. Diminished frontostriatal activity during processing of monetary rewards and losses in pathological gambling. Biol Psychiatry. 2012;71(8):749-757.

67. Fauth-Bühler $M$, Zois $E$, Vollstädt-Klein $S$, Lemenager $T$, Beutel $M$, Mann K. Insula and striatum activity in effort-related monetary reward processing in gambling disorder: the role of depressive symptomatology. Neuroimage Clin. 2014;6:243-251.

68. Balodis IM, Potenza MN. Anticipatory reward processing in addicted populations: a focus on the monetary incentive delay task. Biol Psychiatry. 2015;77(5):434-444.

69. Beck A, Schlagenhauf F, Wustenberg T, et al. Ventral striatal activation during reward anticipation correlates with impulsivity in alcoholics. Biol Psychiatry. 2009;66(8):734-742.

70. Potenza MN, Leung HC, Blumberg HP, et al. An fMRI Stroop study of ventromedial prefrontal cortical function in pathological gamblers. Am J Psychiatry. 2003;160(11):1990-1994.

71. Potenza MN, Steinberg MA, Skudlarski $P$, et al. Gambling urges in pathological gamblers: an fMRI study. Arch Gen Psychiatry. 2003;60(8):828836.

72. Tanabe J, Thompson L, Claus E, Dalwani M, Hutchison K, Banich MT. Prefrontal cortex activity is reduced in gambling and nongambling substance users during decision-making. Hum Brain Mapp. 2007;28(12):1276-1286.

73. Reuter J, Raedler T, Rose M, Hand I, Glascher J, Buchel C. Pathological gambling is linked to reduced activation of the mesolimbic reward system. Nat Neurosci. 2005;8(2):147-148.

74. Limbrick-Oldfield EH, Mick I, Cocks RE, et al. Neural substrates of cue reactivity and craving in gambling disorder. Trans/ Psychiatry. 2017;7(1):e992.

75. Kober H, Lacadie C, Wexler BE, Malison RT, Sinha R, Potenza MN. Brain activity during cocaine craving and gambling urges: an fMRI study. Neuropsychopharmacology. 2016;41(2):628-637.

76. Yang BZ, Balodis IM, Lacadie CM, Xu J, Potenza MN. A preliminary study of $D B H$ (encoding dopamine beta-hydroxylase) genetic variation and neural correlates of emotional and motivational processing in individuals with and without pathological gambling. J Behav Addict. 2016;5(2):282-292.

77. Grant JE, Odlaug BL, Chamberlain SR, Hampshire A, Schreiber LR, Kim SW. A proof of concept study of tolcapone for pathological gambling: relationships with COMT genotype and brain activation. Eur Neuropsychopharmacol. 2013;23(11):1587-1596.

78. Guillot CR, Fanning JR, Liang T, Bermand ME. COMT associations with disordered gambling and drinking measures. J Gamb/ Stud. 2015;31(2):513524.

79. Worhunsky PD, Malison RT, Rogers RD, Potenza MN. Altered neural correlates of reward and loss processing during simulated slot-machine fMRI in pathological gambling and cocaine dependence. Drug A/cohol Depend. 2014;145:77-86.

80. Worhunsky PD, Potenza MN, Rogers RD. Functional brain networks associated with loss-chase decision-making in pathological gambling and cocaine dependence. Drug Alcohol Depend. 2017;178:363-371.

81. Yip SW, Worhsunky PD, Xu J, et al. Gray-matter relationships to diagnostic and transdiagnostic features of drug and behavioral addictions. Addict Biol. 2017 Feb 1. Epub ahead of print. doi:10.1111/adb.12492. 
82. Beveridge TJ, Gill KE, Hanlon CA, Porrino LJ. Parallel studies of cocaine-related neural and cognitive impairment in humans and monkeys. Phil Trans Royal Soc B. 2008;363(1507):3257-3266.

83. Insel T, Cuthbert B, Garvey M, et al. Research Domain Criteria (RDoC): toward a new classification framework for research on mental disorders. Am J Psychiatry. 2010;167(7):748-751.

84. Yip SW, Potenza MN. Application of Research Domain Criteria to childhood and adolescent impulsive and addictive disorders: implications for treatment. Clin Psychol Rev. 2016 Nov 9. Epub ahead of print. doi:10.1016/j.cpr.2016.11.003.

85. Young K. Psychology of computer use: XL. Addictive use of the Internet: a case that breaks the stereotype. Psychol Rep. 1996;79(3 pt 1):899-902.

86. Petry NM, O'Brien CP. Internet gaming disorder and the DSM-5. Addiction. 2013;108(7):1186-1187.

87. Brand M, Young K, Laier C, Wölfling K, Potenza MN. Integrating psychological and neurobiological considerations regarding the development and maintenance of specific Internet-use disorders: an Interaction of Person-Affect-Cognition-Execution (I-PACE) model. Neurosci Biobehav Rev. 2016;71:252-266.

88. Aarseth $\mathrm{E}$, Bean AM, Boonen $\mathrm{H}$, et al. Scholars' open debate paper on the World Health Organization ICD-11 Gaming Disorder proposal. J Behav Addict. 2016 Dec 30:1-4. Epub ahead of print. doi:10.1556/2006.5.2016.088. 89. Saunders JB, Hao W, Long J, et al. Gaming disorder: its delineation as an important condition for diagnosis, management and prevention. J Behav Addict. In press.

90. Banz B, Yip SW, Yau YHC, Potenza MN. Behavioral addictions in addiction medicine: from mechanisms to practical considerations. Prog Brain Res. 2016;223:311-328.

91. Fauth-Bühler M, Mann K. Neurobiological correlates of internet gaming disorder: similarities to pathological gambling. Addict Behav. 2017:64:349-356.

92. Wölfling K, Beutel ME, Dreier M, Müller KW. Treatment Outcomes in Patients with Internet Addiction: a clinical pilot study on the effects of a cognitive-behavioral therapy program. Biomed Res Int. 2014;2014:425924. 93. Zhang JT, Yao YW, Potenza MN, et al. Effects of craving behavioral intervention on neural substrates of cue-induced craving in Internet gaming disorder. Neuroimage Clin. 2016;12:591-599.

94. Zhang JT, Yao YW, Potenza MN, et al. Altered resting-state neural activity and changes following a craving behavioral intervention for Internet gaming disorder. Sci Rep. 2016;6:28109.
95. Dong G, Potenza MN. A cognitive-behavioral model of Internet gaming disorder: theoretical underpinnings and clinical implications. J Psychiatr Res. 2014;58:7-11.

96. Dong G, Lin X, Potenza MN. Decreased functional connectivity in an executive control network is related to impaired executive function in Internet gaming disorder. Prog Neuropsychopharmacol Biol Psychiatry. 2015;57:76-85.

97. Liu L, Xue G, Potenza MN, et al. Dissociable neural process alterations during risky decision-making in individuals with Internet-gaming disorder. Neuroimage Clin. 2017:14:741-749.

98. Krueger RB. Diagnosis of hypersexual or compulsive sexual behavior can be made using ICD-10 and DSM-5 despite rejection of this diagnosis by the American Psychiatric Association. Addiction. 2016;111(12):2110 2111.

99. Kor A, Fogel Y, Reid R, Potenza MN. Should hypersexual disorder be classified as an addiction? Sex Addict Compulsivity. 2013;20(1-2). doi:10.108 0/10720162.2013.768132.

100. Kraus SW, Voon V, Potenza MN. Should compulsive sexual behavior be considered an addiction? Addiction. 2016;111(12):2097-2106.

101. Kraus SW, Voon V, Potenza MN. Neurobiology of compulsive sexua behavior: emerging science. Neuropsychopharmacology. 2016;41(1):385386.

102. Voon V, Mole $T$, Banca $P$, et al. Neural correlates of sexual cue reactivity in individuals with and without compulsive sexual behaviours. PLOS One. 2014;9(7):e102419.

103. Gola M, Wordecha M, Sescousse G, et al. Can pornography be addictive? An fMRI study of men seeking treatment for problematic pornography use. Neuropsychopharmacology. 2017 Apr 14. Epub ahead of print. doi:10.1038/npp.2017.78

104. Mechelmans DJ, Irvine M, Banca P, et al. Enhanced attentional bias towards sexually explicit cues in individuals with and without compulsive sexual behaviours. PLoS One. 2014;9(8):e105476.

105. Banca P, Morris LS, Mitchell S, Harrison NA, Potenza MN, Voon V. Novelty, conditioning and attentional bias to sexual rewards. J Psychiatr Res. 2016;72:91-101.

106. Kraus SW, Meshberg-Cohen S, Martino S, Quinones LJ, Potenza MN. Treatment of compulsive pornography use with naltrexone: a case report. Am J Psychiatry. 2015;172(12):1260-1261.

107. Potenza MN. Behavioural addictions matter. Nature. 2015;522(7557):S62. 


\section{Consideraciones clínico neuropsiquiátricas relacionadas con las adicciones conductuales}

Durante las últimas décadas, las conductas relacionadas con el juego, el juego en internet y el sexo han recibido gran atención como posibles focos de adicciones no asociadas con el uso de sustancias En este artículo se revisará la historia reciente y el estado actual de las adicciones conductuales o no relacionadas con sustancias. Se pondrá especial atención en el juego y en el trastorno del juego, dado que este último es actualmente el único trastorno adictivo no relacionado con sustancias descrito en el texto principal de la quinta edición del Manual Diagnóstico y Estadístico de los Trastornos Mentales (DSM-5). Además se revisará el trastorno de juegos en internet, actualmente en la sección del DSM-5 dedicada a aquellas condiciones que requieren de investigación adicional, al igual que el concepto de adicción a internet. También serán abordadas las conductas sexuales compulsivas (incluyendo el uso problemático de la pornografía), especialmente en relación a cómo podrán ser consideradas las adicciones conductuales en la próxima edición número 11 de la Clasificación Internacional de Enfermedades (CIE-11).

\section{Réflexion clinique neuropsychiatrique sur les addictions non liées à la consommation de substance ou comportementales}

Ces dernières décennies, les comportements non liés à la consommation de substances comme les troubles liés au jeu d'argent, au jeu en général et au sexe sont pris en compte comme de possibles foyers d'addictions. Dans cet article, nous analysons l'histoire récente et la situation actuelle des addictions non liées à la consommation de substance ou comportementales. Nous nous intéresserons particulièrement au jeu d'argent pathologique et aux troubles qui y sont liés, ces derniers étant actuellement les seuls troubles addictifs non liés à une substance décrits dans le texte principal de l'actuelle (5e) édition du Diagnostic and Statistical Manual of Mental Disorders (DSM-5). L'addiction aux jeux vidéo en ligne, actuellement dans le chapitre du DSM-5 concernant les affections nécessitant des recherches supplémentaires, sera aussi prise en compte, tout comme le concept d'addiction à Internet. Les comportements sexuels compulsifs (comme l'utilisation problématique de la pornographie) seront envisagés, en particulier quant à la façon d'examiner les addictions comportementales dans la 11e édition de I'ICD-11 (International Classification of Diseases) à venir. 